\title{
BARRIERS OF SMES' SUSTAINABILITY IN SUB-SAHARAN AFRICA: A PLS-SEM APPROACH
}

\author{
John Amoah \\ Tomas Bata University, Faculty of Management and Economics, Zlin, Czech Republic \\ Pentecost University, Department fo Services and Marketing, Accra, Ghana \\ Email: $\underline{\text { amoah@utb.cz }}$
}

\author{
Abdul Bashiru Jibril \\ Tomas Bata University, Faculty of Management and Economics, Zlin, Czech Republic \\ Sunyani Technical University, Faculty of Business and Management Studies, Sunyani, Ghana. \\ Email: jibril@utb.cz \\ Bayuasi Nammei Luki \\ Ghana Communication Technology University, Faculty of Information Technology Business \\ Email: blukki@gctu.edu.gh \\ Michael Amponsah Odei \\ Tomas Bata University, Faculty of Management and Economics, Zlin, Czech Republic \\ Email: Odei@,utb.cz \\ Charles Yawson \\ Ghana Communication Technology University, Faculty of Information Technology Business \\ Email: yawson@gctu.edu.gh
}

Received: 26 March 2021. Revision received: 10 May 2021. Accepted: 21 May 2021

\begin{abstract}
Undoubtedly, entrepreneurial knowledge is a prerequisite for the survival of every business organization. To this, the contribution of Small and Medium Enterprises (SMEs) in the socio-economic development in most developing economies cannot be underestimated. Both developed and developing countries are living testimonies of their contributions to their nation's growth and development. However, extant literature shows that as competition and innovation intensify in the global business market, many SMEs in developing countries are constrained by external forces that hinder the sustainability of these businesses. Hence, this paper aims to find out the mitigating factors warranting SMEs' sustainability from the viewpoint of entrepreneurs and business owners, particularly in the manufacturing sector of Ghana, a Sub-Saharan Africa region. To achieved this objective, the study deployed a simple random sampling technique with 370 valid responses through a structured questionnaire for the analysis. Relying on PLS-SEM (partial least square and structural modeling) with the aid of ADANCO 2.2.1 software version revealed that factors such as financial challenges, technology; market penetration \& acceptability; and research \& development are barriers facing SMEs sustainability in the Ghanaian manufacturing sector. This study would be beneficial to entrepreneurs and business owners of SMEs in most developing countries and provide deeper insight into the SME literature at large. This study would further strengthen SME entrepreneurs and business owners to fully devise strategies that can help them to override such migrating challenges and equipped them to effectively stay competitive in the long term for the firm's growth and survival. The limitation and future research directions are equally presented in the paper.
\end{abstract}

KEYWORDS: Mitigating factors, SMEs, sustainability, developing country, Ghana

JEL CLASSIFICATION: K22, L26, M21

Reference: Amoah, J., Jibril, A.B., Luki, B.N., Odei, M.A. \& Yawson, C. (2021). Barriers of SMEs' sustainability in subsaharan Africa: a pls-sem approach. International Journal of Entrepreneurial Knowledge, 9(1), 10-24. doi: 10.37335/ijek.v9i1.129

\section{INTRODUCTION}




\section{INTERNATIONAL JOURNAL OF ENTREPRENEURIAL KNOWLEDGE}

Issue 1, volume 9, ISSN 2336-2960 (Online)

www.ijek.org

The immense contributions of Small and Medium Enterprises (SMEs) in the entire world cannot be underestimated (Sanjo \& Ibrahim, 2017; Jibril, Kwarteng, \& Chovancova, 2019). SMEs are well known for contributing about 40\% to Gross Domestic Product (GDP) and 70\% creation of employment opportunities (Qalati et al., 2021; Chatterjee \& Kumar 2020; Virglerova et al., 2020; Ye \& Kulathunga, 2019; Belas et al., 2020; Kiram \& Saputra 2021). SMEs, therefore, play a major role in the growth and development of both developed and developing countries (Pandya 2012; Lazányi, \& Amoah, 2020). According to Pandya, (2012), SMEs in most developing countries are noted to perform crucial functions like poverty reduction, improving income distribution, job creation, and also contribute to export growth. Such contributions lead to entrepreneurship, industry, and the rural economy. Similarly, Amoah \& Jibril (2020); Kachembere, (2011) noted that SMEs are well known for promoting grassroots economic growth and contribute massively to social development and poverty reduction. Across countries and industries, the description for SMEs differs. Thus, defining SMEs in the Ghanaian environment is significant. The definition of SMEs has become very difficult to come by since every country has its definition based on the variables used in defining it (Salikin et al., 2014; Kwaku Amoah, 2018). However, Abor \& Quartey, (2010) defined Ghanaian SMEs by using their workforces by classifying them like 0-9 micro, 10-99 small, and 100-499 as a medium enterprise. Also, the Ghana Statistical Service (GSS) classifies any enterprise or business entity that employs between 1 to 5 as micro, 6 to 30 as small, 31-100 as a medium, and more than 100 workers as a large enterprise (Amoah \& Amoah, 2018). In the same publication, fixed assets value was subsequently used in giving a clearer definition of SMEs. In the same vein, National Board for Small Scale Industries (NBSSI) mandated to control the activities of SMEs in Ghana also defined SMEs using its employees and fixed assets as the basic criterion. Based on the dynamism of the operation and formation of SMEs, they are noted generally to be controlled by one individual, probably the owner/entrepreneur who takes the majority of the decisions.

Despite the numerous contributions offered by SMEs in a developing nation like Ghana, they are consistently faced with some mitigating factors warranting their sustainability (Kwarteng, Jibril, Nwaiwu, Pilik, \& Ali, 2019; Qalati et al. 2021). Factors affecting SMEs' sustainability are well researched especially in both developed and developing economies. Since the 2008/2009 global economic crisis, various governments both developed and developing countries have paid serious attention to SMEs because of the critical role they play in poverty reduction, job creation, and social cohesion (Qalati et al. 2021). Such mitigating factors however limit the sustainability period of SMEs from one stage to another. These factors invariably affect the sustainability of SMEs making it difficult for business owners/entrepreneurs to enjoy long-term benefits. Hence, it is very important and useful to understand the impacts of such factors on SME's sustainability and how these factors can be eliminated or improved in the long term. The present study, therefore, investigates the mitigating factors such as financial challenges, research and development, market penetration and acceptability, and technology to establish their impacts on SMEs' sustainability. The research question that will fulfill the aim of the present study is as follows: Do these mitigating factors affect SMEs' sustainability in the context of a developing nation and in what ways do these factors affect SMEs sustainability? In this study, the findings will be beneficial to entrepreneurs, business owners, and SME managers to devise measures and strategies that can be used to eliminate or control such factors to enjoy sustainability. Theoretically, the present study will contribute adequately to fill the missing gap in the literature that has existed for some time in the context of developing nations' perspectives. The present study, therefore, contains the following: literature review, methodology, empirical results/findings, discussions, and conclusion and finally backed with limitation at the end of the paper. 


\section{INTERNATIONAL JOURNAL OF ENTREPRENEURIAL KNOWLEDGE}

Issue 1, volume 9, ISSN 2336-2960 (Online)

www.ijek.org

\section{LITERATURE REVIEW}

\subsection{Financial Challenges}

Though a plethora of scholarly works have been conducted in other countries, little attention is paid to Ghana. The literature revealed that SMEs faced a myriad of challenges in developing countries that hinder their sustainability notably financial challenges ( Amoah \& Jibril, 2020; Kwaku Amoah, 2018). Wang (2016) conducted a study using cross-country data from the World Bank Enterprise Survey among 119 developing countries. The study sought to investigate the major factors warranting SME sustainability among these emerging economies. The findings unearthed that access to finance was found to be 23.1 points more a mitigating factor warranting SMEs sustainability compare to larger firms. The study concluded that the most significant factors warranting SME's sustainability were financial challenges. This factor has invariably affected SME sustainability. According to Pandya, (2012) financial challenges have always been the major challenge confronting SMEs in most developing countries. This has led to SMEs only enjoying short-term sustainability periods in operation. Eniola (2014) researched the role of SME Firm Performance in Nigeria and strongly established that the most difficult challenge of SMEs in developing countries is financial challenges. This challenge sometimes forced SMEs to contract loans and other financial assistance at a higher interest rate to support and also to maintain their operational activities. Therefore, governments and state institutions mandated to control SMEs have made some concerted efforts to support SMEs in diverse ways especially financially. However, Bloom et al., (2010) researched why do firms in developing countries have low productivity and concluded that financial challenges have crippled SMEs found in most developing countries with Ghana also affected. Therefore, the lack of access to finance has significantly affected SME sustainability. Thus, access to finance is an underlying factor that warrants the progress of small and medium enterprises in developing countries (Pournasir, 2013).

\subsection{Research and Development}

Besides, another research by Ensari \& Karabay (2014) to ascertain the main factors that affect the sustainability and success of SMEs across different industries underscored that factors affecting SMEs sustainability vary from country to country because of cultural, economic, technological, political, and geographical differences. Their mitigating factors were categorized into internal and external factors. In general, they concluded that research and development are considered to be one of the major factors warranting the sustainability of SMEs. A similar study by Abor \& Quartey, (2010) established that lack of research and development has impacted negatively on products and services innovations of SMEs, products and services quality, and lack of marketing strategies to meet customers or consumers demand. Due to a lack of research and development, the products and services of most SMEs are not able to meet domestic and international standards (see Jibril, Kwarteng, Chovancová, \& Denanyoh, 2019). Ahmedova (2015) revealed that research and development is an essential key and cannot be underestimated. The said publication publicly established that research and development lead to innovations, improvement in SMEs operational activities, products and service quality, easy access to finance among others. Additionally, Ahmedova (2015), who did a study on the sustainability and competitiveness of SMEs indicated that a favorable business environment is a panacea to SMEs' sustainability. The favorable business environment in his studies encapsulates easy access to finance, innovation and technological activities, investment in research and development, market penetration, and intellectual property rights. Ahmedova concluded that SMEs' access to new markets, investing in research and development, and access to finance will lead to the necessary conditions that will propel their sustainability and competitiveness. This shows that access to finance, technology, and new markets are very influential in SMEs' sustainability in both developed and under-developed economies. 


\section{INTERNATIONAL JOURNAL OF ENTREPRENEURIAL KNOWLEDGE}

Issue 1, volume 9, ISSN 2336-2960 (Online)

www.ijek.org

\subsection{Market Penetration and Acceptability}

An interesting dimension to the debate of SMEs sustainability is gradually evolving regarding the nature of SMEs and the barriers to their sustainability (Wang, 2016). SMEs continue to face market penetration and acceptability in both local and international. This has negatively limited their sustainability period in operations. The inability of SMEs to penetrate the market both locally and internationally has retarded their profitability and long-term viability. White et al (2014), further revealed that the acceptability of products and services from SMEs in developing countries has been very challenging as compared to developed countries. This factor has impeded the progress and warranting small and medium enterprise sustainability. Abou-Shouk et al, (2016) noted that products and services from small and medium enterprises in most developing countries are not generally accepted on the international markets with the view of their quality and standard. Such challenges have been attributed to a lack of support in the form of tax rebates, subsidies which are not mostly available to cushion SMEs to meet the standardization requirements of their products and services in both local and global markets. Nnadi, (2014) researched on Entrepreneurship Development and its Impact on Small Scale Business Enterprises in Developing Countries: A Nigerian Experience. The said publication revealed that political instability has become critical to the acceptability of products and services from this part of the world. Such incident has made it difficult for SMEs found in such countries to partner with continental and international companies for businesses. The organizational context was also considered by Maduku et al., (2016) as one of the key variables that affect the international acceptability of products and services from developing countries. This factor has castigated SMEs' failure and sustainability. Small and medium enterprises face international market acceptability challenges due to a lack of physical infrastructure and logistics. However, the ability of SMEs to be accepted on the international market is critical to boosting their sustainability. Yet, the competitive environment they find themselves, as well as other factors, exclude them from enjoying these gains (Haseeb et al., 2019).

\subsection{Technology}

Although the world is currently under globalization to the existence of ICT, SMEs in most developing countries still manage their business with traditional approaches. This has resulted in low productivity, low quality of products and services to local and international markets (Pandya, 2012). A study conducted by Qalati et al. (2021) on technology adoption and SMEs sustainability in developing countries using PLS-SEM among 423 SME owners, business executives and managers revealed that technology was a critical factor to SMEs sustainability. Generally, it is noted that SMEs have low productivity as a result of a lack of modern-day sophisticated machinery that could improve upon their operational activities. Such incidence still exists due to a lack of access to financial assistance as compared to SMEs in the developed countries. This assertion by Qalati et al (2021) was confirmed by Denicolai et al., (2021) research which explored the effect of technology on SMEs' sustainability among 438 local and international SMEs and confirmed that technology is a significant factor in SMEs growth and sustainability. They were also sanguine to add that having technology alone is not enough for SMEs' sustainability but that SMEs' ability to remain competitive and sustainable depends on how they recognize and apply technology. Singh et al., (2019) also conducted a similar study on the application of technology as a means to SMEs sustainability in the Indian food industry using Grey Based Decision Making Trial and Evaluation Laboratory (Grey-DEMATEL). Their research also revealed that the SMEs in the food industry in India faced so many challenges that stifle their sustainability. The topmost among them are financial access and technology. Their findings on technology and financial access are consistent with Denicolai et al., (2021) and Wang (2016) respectively. 


\section{INTERNATIONAL JOURNAL OF ENTREPRENEURIAL KNOWLEDGE}

Issue 1, volume 9, ISSN 2336-2960 (Online)

www.ijek.org

\subsection{Sustainability}

Does the nature of ownership of the SME present opportunities for its growth and sustainability? Studies have shown that private firms progress faster than state-owned enterprises. This according to Yin (2012) and Wang (2016) is partly because state-owned enterprises focus on employment expansion instead of efficient and effective utilization of resources. Ji (2011) and Yin (2012) came to their conclusion saying that state-owned enterprises are too big to fail and as such face fewer obstacles to their sustainability, not just financial challenges but also research and development. These and many other incentives give stateowned enterprises greater growth and sustainability prospects compare to SMEs. This means that SMEs are more likely to perceive access to capital, new markets, and technology as a constraint to their sustainability compare with larger firms. The World Bank Enterprise Survey for the period between 2006 and 2009 indicates that about $31 \%$ of SMEs that were studied revealed that access to capital and new markets were the most significant factors to their sustainability. The survey showed that about $40 \%$ of the SMEs also had less than 3 years of trading experience (age) in their respective industries. Research by Chavis et al., (2010) and Wang (2016) elucidated that firms who have not had substantial trading experience in their industries of operation are more likely to rely on informal financings such as personal savings, loans from family and friends compare to firms who have been in the industry for long. A wealth of relevant literature showed that mitigating factors warranting the sustainability of SMEs can be classified into political, market penetration, access to capital, research and development, employee commitment, technology, managerial and technical skills, access to the needed raw materials among others. As can be noticed in the above literature, mitigating factors warranting SMEs' sustainability vary a great deal and have to be narrowed down. As a matter of practicality, our analysis will be limited to only four key mitigating factors, thus, Financial, Research, and Development, Market Penetration and Acceptability, and Technology. The researchers will also attempt to find out how these factors might be controlled or improved for SMEs to enjoy sustainability.

\section{AIM, METHODOLOGY, AND DATA}

\subsection{Summary of hypotheses development}

To reiterate our study focus, this paper aimed to explore the mitigating factors warranting SMEs' sustainability from the viewpoint of entrepreneurs and business owners, particularly in the manufacturing sector of Ghana, a Sub-Saharan Africa region. In doing so, four (4) hypotheses where developed from the literature reviewed to aid the quantitative approach of the study. In other words, based on the relevant empirical literature reviewed, the following hypotheses were deduced:

H1: Lack of access to finance would significantly affect SME's sustainability.

H2: Lack of research and development would negatively affect the Sustainability of SMEs.

H3: Failure of market penetration and product acceptability would significantly affect SMEs' sustainability.

H4: Lack of modern-day technology by SMEs would negatively affect their sustainability.

\subsection{Sample Data and Demographics}

Since the researchers had in mind to test the research hypotheses, a questionnaire was comprehensively developed and distributed to the target SMEs through the online survey approach and self-administered questionnaire. To be more precise, google drive was extensively used in collecting the data through the online mode whereby the self-administered questionnaire was delivered to the premises of the selected organizations with COVID-19 protocols duly observed. The online mode has been recently used by scholars and researchers (Amoah et al., 2021; Amoah \& Jibril 2020; Haseeb et al., 2019). The Likert scale questionnaire was designed containing twenty-seven (27) self-evaluation questions in the form of 
INTERNATIONAL JOURNAL OF ENTREPRENEURIAL KNOWLEDGE

Issue 1, volume 9, ISSN 2336-2960 (Online)

www.ijek.org

statements with five options ranging from 1-5, where 1 stands for completely disagree and 5 stands for Completely agree. The adoption of the Likert scale was used to ascertain the level of respondents' understanding of the questions. Moreover, the data was collected from SMEs in the manufacturing sector of the economy from the central and western parts of the country. The manufacturing sector is regarded as one of the strong pillars contributing immensely to the growth and development of the country in diverse ways. Again, it is important to state that this manufacturing sector in which our sampled was drawn from consist of aluminium smelting firm, food processing firm, cement firm, and small commercial ship building firm. The data was collected in February and March 2021. The questionnaire was answered by business owners, managerial staff, and employees of the selected organizations. In all, 450 questionnaires were distributed to the targeted participants of which 410 were answered and returned. On top of that, 370 responses were correctly filled and were good for the data processing and analysis. A simple random probability sampling technique was used in selecting the respondents needed in the answering of the questionnaire. Averagely, each respondent used eight minutes to answer the questionnaire and quit from the online site after answering. The respondents were advised not to write their names and details on the questionnaire because of ethical standards in academia. Finally, the 370 responses received were analyzed through Partial Least Square-Structural Equation Modeling (PLS-SEM) ADANCO 2.2.1 version, with details shown in Table 1 below.

Table 1 Structure of respondents according to selected demographic characteristics

\begin{tabular}{|c|c|c|c|}
\hline Details & & Frequency & Percentage $(\%)$ \\
\hline \multirow[t]{2}{*}{ Gender } & Male & 241 & 65.2 \\
\hline & Female & 129 & 34.8 \\
\hline \multirow[t]{6}{*}{ Age } & $20-25$ & 28 & 7.7 \\
\hline & $26-30$ & 75 & 20.3 \\
\hline & $31-35$ & 84 & 22.7 \\
\hline & $36-40$ & 84 & 22.7 \\
\hline & $41-45$ & 47 & 12.6 \\
\hline & Above 46 & 52 & 14.0 \\
\hline \multirow[t]{4}{*}{ Educational } & Senior High School & 41 & 11.0 \\
\hline & Diploma/HND & 79 & 21.3 \\
\hline & Bachelor Degree & 134 & 36.2 \\
\hline & Masters/PGD & 116 & 31.5 \\
\hline \multirow[t]{4}{*}{ Company Size } & Micro(1-20 employees) & 54 & 14.50 \\
\hline & Small (21-60 employees) & 71 & 19.30 \\
\hline & Medium(1-100 employees) & 91 & 24.6 \\
\hline & Large(100 above) & 154 & 41.50 \\
\hline \multirow{4}{*}{$\begin{array}{l}\text { Work } \\
\text { Experience }\end{array}$} & $1-5$ years & 125 & 33.8 \\
\hline & $6-10$ years & 104 & 28.0 \\
\hline & $10-15$ years & 77 & 20.8 \\
\hline & 15 and above & 64 & 17.4 \\
\hline \multirow{4}{*}{$\begin{array}{l}\text { Manufacturing } \\
\text { type }\end{array}$} & Food processing & 142 & 38.4 \\
\hline & Aluminum & 51 & 13.8 \\
\hline & Cement and block molding & 78 & 21.1 \\
\hline & Ship/canoe building & 99 & 26.8 \\
\hline
\end{tabular}


INTERNATIONAL JOURNAL OF ENTREPRENEURIAL KNOWLEDGE

Issue 1, volume 9, ISSN 2336-2960 (Online)

www.ijek.org

\begin{tabular}{|l|l|c|c|}
\hline \multirow{2}{*}{ Location } & Western region/western north & 217 & 58.6 \\
\cline { 2 - 4 } & Central region & 153 & 41.4 \\
\hline Total $(\mathrm{n})$ & & 370 & 100 \\
\hline
\end{tabular}

(Source: Authors' field survey results: February 2021 \& March 2021)

\subsection{Data Analysis Technique}

Since the research model needs to be tested, the researchers relied on Partial Least Square-Structural Equation Modeling (PLS-SEM) using ADANCO Version 2.2.1. The use of PLS-SEM statistical software is appropriate to be adopted in this present study since scholars and researchers in recent times such as (Amoah \& Jibril 2020; Haseeb et al., 2019; Adzovie \& Jibril 2020) have used it in their publications. Since Co-variance-based structural equation modeling (CB-SEM) requires data to be normally distributed, the PLS-SEM holds a different assumption on data distribution which makes it a perfect statistical software to be used in processing the data of this present study. Also, PLS-SEM measures the connection between the constructs and the variables at the same time as revealed by (Hair et al., 2019; Hair et al., 2017), thus, best to be adopted when conducting exploratory studies (Henseler et al., 2016; Jibril et al., 2019). Smart PLS 3.2.9 was used for the research hypotheses testing.

\section{EMPIRICAL RESULTS AND DISCUSSION}

\subsection{Model measurement}

The constructs' reliability was vigorously assessed through Dijkstra-Henseler's rho along with Cronbach's alpha coefficients per the literature of PLS-SEM (Hair et al., 2019). As found in table 2 below, all the threshold values exceeded the minimum requirement of 0.5 as revealed by Hair et al., (2019) indicating how strong the coefficients of the reliability of the constructs are. ADANCO 2.2.1 version was subsequently used to assess the psychometric properties of the constructs and the underlying items as established by (Henseler \& Dijkstra, 2015). In establishing the composite reliability determinant, both Jöreskog's rho $(p c)$ and Dijkstra-Henseler's rho $(\varrho A)$ met the requirement with the threshold of 0.7 and 0.8 respectively as shown in table 2 below. In view of this, the results presented by Dijkstra-Henseler's rho ( $\mathrm{QA}$ ) shows 0.8234 and 0.8897 as the minimum and maximum coefficients respectively, while convergent validity was presented by average variance extracted (AVE) which also met the minimum requirement threshold of 0.5 (see table 2).

Table 2 Construct reliability and validity

\begin{tabular}{lllll}
\hline Constructs & $\begin{array}{l}\text { Dijkstra-Henseler's } \\
\text { rho }(\mathrm{eA})\end{array}$ & $\begin{array}{l}\text { Jöreskog's } \\
(\mathrm{\varrho c})\end{array}$ & $\begin{array}{l}\text { rho } \\
\text { alpha }(\alpha)\end{array}$ & $\begin{array}{l}\text { Cronbach's } \\
\text { extracted (AVE) }\end{array}$ \\
\hline $\begin{array}{l}\text { Financial } \\
\text { Challenges }\end{array}$ & 0.8702 & 0.8979 & 0.8577 & 0.6483 \\
$\begin{array}{l}\text { Research \& } \\
\text { Development }\end{array}$ & 0.8897 & 0.9020 & 0.8643 & 0.7458 \\
& & & &
\end{tabular}


INTERNATIONAL JOURNAL OF ENTREPRENEURIAL KNOWLEDGE

Issue 1, volume 9, ISSN 2336-2960 (Online)

www.ijek.org

\begin{tabular}{lcccc} 
Market & 0.8234 & 0.9214 & 0.8863 & 0.6494 \\
$\begin{array}{l}\text { Penetration and } \\
\text { Acceptability }\end{array}$ & & & & \\
$\begin{array}{l}\text { Technology } \\
\text { Sustainability }\end{array}$ & 0.8414 & 0.8809 & 0.8196 & 0.6756 \\
\hline
\end{tabular}

(Source: Authors' processing from ADANCO 2.2.1 version)

Also, on the indicator loadings of the latent construct, all the items were successfully loaded to their corresponding construct. To be more precise, the measured indicators recorded approximately 0.6 and 0.8 as the minimum and maximum loading coefficients. According to Bagozzi \& Yi, (1988), latent loadings with a threshold above 0.6 are the best measurement for a latent variable study of which the results show the same. The indicator variables show 0.5453 as minimum and 0.7962 as maximum respectively as depicted in table 3. Besides, the Variance Inflation Factor (VIF) was also measured through the presence of multicollinearity in detecting the evidence of common method variance (CMV) for the measurement scale.

Table 3 Factor loading and Variance inflation factor (VIF)

\begin{tabular}{|c|c|c|c|c|c|c|}
\hline Indicator & $\begin{array}{l}\text { Financial } \\
\text { challenges } \\
(\mathrm{FC})\end{array}$ & $\begin{array}{l}\text { Research \& } \\
\text { Development } \\
\text { (RD) }\end{array}$ & $\begin{array}{c}\text { Market } \\
\text { Penetration } \\
\& \\
\text { Acceptability } \\
\text { (MPA) }\end{array}$ & $\begin{array}{l}\text { Technolog } \\
\text { y (TG) }\end{array}$ & $\begin{array}{l}\text { Sustainability } \\
\text { (SS) }\end{array}$ & VIF \\
\hline FC1 & 0.6838 & & & & & 2.2878 \\
\hline FC2 & 0.5453 & & & & & 1.7657 \\
\hline FC3 & 0.6608 & & & & & 1.9469 \\
\hline FC4 & 0.6503 & & & & & 1.9834 \\
\hline FC5 & 0.7014 & & & & & 2.1391 \\
\hline RD1 & & 0.7506 & & & & 2.2426 \\
\hline RD2 & & 0.7463 & & & & 2.3655 \\
\hline RD3 & & 0.7962 & & & & 2.7963 \\
\hline RD4 & & 0.6901 & & & & 2.1034 \\
\hline MPA1 & & & 0.5835 & & & 1.7346 \\
\hline MPA2 & & & 0.7222 & & & 2.1234 \\
\hline MPA3 & & & 0.6461 & & & 2.1075 \\
\hline MPA4 & & & 0.6457 & & & 1.9284 \\
\hline TG1 & & & & 0.6073 & & 1.6700 \\
\hline TG2 & & & & 0.7133 & & 1.9967 \\
\hline TG3 & & & & 0.7441 & & 2.1624 \\
\hline TG4 & & & & 0.6378 & & 1.7473 \\
\hline SS1 & & & & & 0.6982 & 2.5723 \\
\hline SS2 & & & & & 0.5746 & 2.1427 \\
\hline SS3 & & & & & 0.6403 & 2.5655 \\
\hline
\end{tabular}


INTERNATIONAL JOURNAL OF ENTREPRENEURIAL KNOWLEDGE

Issue 1, volume 9, ISSN 2336-2960 (Online)

www.ijek.org

SS4

0.6810

2.5356

SS5

0.6262

2.1493

(Source: Author's processing from ADANCO 2.2.1 version)

Moreover, the discriminant validity of the constructs was vigorously assessed through Fornell-Larcker's criterion (1981) as revealed to be appropriate by (Henseler et al., 2015) with results shown in table 4 below. The Average Variance Extracted (AVE) results of the measured constructs are depicted in the diagonal form (in bold) as found in the below table. According to experts like (Hair et al., 2019; Henseler et al., 2015), AVE values must be greater than 0.5 of which all the AVE values met the requirement as shown in the diagonal (bold) form. Moreover, all the constructs of AVE should be of a higher coefficient at both column and row position over other constructs so that discriminant validity could be established. The result shows that the constructs satisfy both basic and stringent assumptions and therefore establishes discriminant validity.

Table 4 Test of discriminant validity - Fornell-Larcker criterion

\begin{tabular}{|c|c|c|c|c|c|}
\hline Constructs & 1 & 2 & 3 & 4 & 5 \\
\hline 1=Sustainability & 0.6380 & & & & \\
\hline $2=$ Financial & 0.5778 & 0.6483 & & & \\
\hline \multicolumn{6}{|l|}{ Challenges } \\
\hline 3= Research \& & 0.5136 & 0.5011 & 0.7458 & & \\
\hline \multicolumn{6}{|l|}{ Dev. } \\
\hline 4=Mkt. Pene.\& A & 0.5883 & 0.5548 & 0.5898 & 0.6494 & \\
\hline 5=Technology & 0.5688 & 0.4562 & 0.4565 & 0.5978 & 0.6756 \\
\hline
\end{tabular}

Note: the diagonal (in bold) are the average variance extracted (AVE) Sources: Author's processing from ADANCO 2.2.1 version

\subsection{Structural modeling- Path analysis}

The researchers also realized that it is important to assess both the model fit and path analysis. Noticeably, it is important to establish this analysis because it eventually establishes the casual-effect (relationship) of the research constructs underlined. Regarding the predictive power (coefficient of determination) of the research constructs, the coefficients of determination of the regression model were duly assessed. The percentage variation of the coefficients indicates the dependent variable that has been explained by the predictor (independent) variable. The depicted Table 5 shows the regression coefficients; Beta $(\beta)$, and the significant values; $\mathrm{T}$-values $>1.96$ (or $\mathrm{P}$-values $<0.05$ ). Therefore, $\mathrm{R}^{2}$ of the predictor variable of $71 \%$ is also appropriate as shown in Table 5 and Figure 1 respectively.

\section{Table 5 Hypothetical path coefficient}

Standard bootstrap results 
INTERNATIONAL JOURNAL OF ENTREPRENEURIAL KNOWLEDGE

Issue 1, volume 9, ISSN 2336-2960 (Online)

www.ijek.org

\begin{tabular}{|c|c|c|c|c|c|c|c|}
\hline Relationship & $\begin{array}{l}\text { Beta } \\
(\beta)\end{array}$ & $\begin{array}{l}\text { Mean } \\
\text { value }\end{array}$ & $\begin{array}{l}\text { SD } \\
\text { error }\end{array}$ & t-value & $\begin{array}{l}\text { Effect } \\
\text { size } \\
\text { (Cohen's } \\
\text { f }^{2} \text { ) }\end{array}$ & $\begin{array}{l}\text { P- } \\
\text { value }\end{array}$ & $\begin{array}{l}\text { Empirical } \\
\text { remarks }\end{array}$ \\
\hline $\mathrm{H} 1: \mathrm{FC}->\mathrm{SS}$ & 0.3132 & 0.3133 & 0.0650 & 4.8210 & 0.1324 & 0.0000 & Supported \\
\hline H2:RD-> SS & 0.1489 & 0.1509 & 0.0614 & 02.4235 & 0.0280 & 0.0078 & Supported \\
\hline H3: MPA -> SS & 0.1930 & 0.1952 & 0.0973 & 1.9838 & 0.0343 & 0.0238 & Supported \\
\hline H4: TG -> SS & 0.2928 & 0.2894 & 0.0640 & 4.5742 & 0.1116 & 0.0000 & Supported \\
\hline Independent variable: & \multicolumn{4}{|c|}{ Coefficient of determination $\left(\mathrm{R}^{2}\right)$} & \multicolumn{2}{|c|}{ Adjusted $\mathrm{R}^{2}$} & \\
\hline Sustainability & \multicolumn{4}{|c|}{0.7137} & \multicolumn{2}{|c|}{0.7105} & \\
\hline
\end{tabular}

Note SS = Sustainability. Sources: Authors'processing from ADANCO 2.2.1 version

Figure 1 Estimated research model

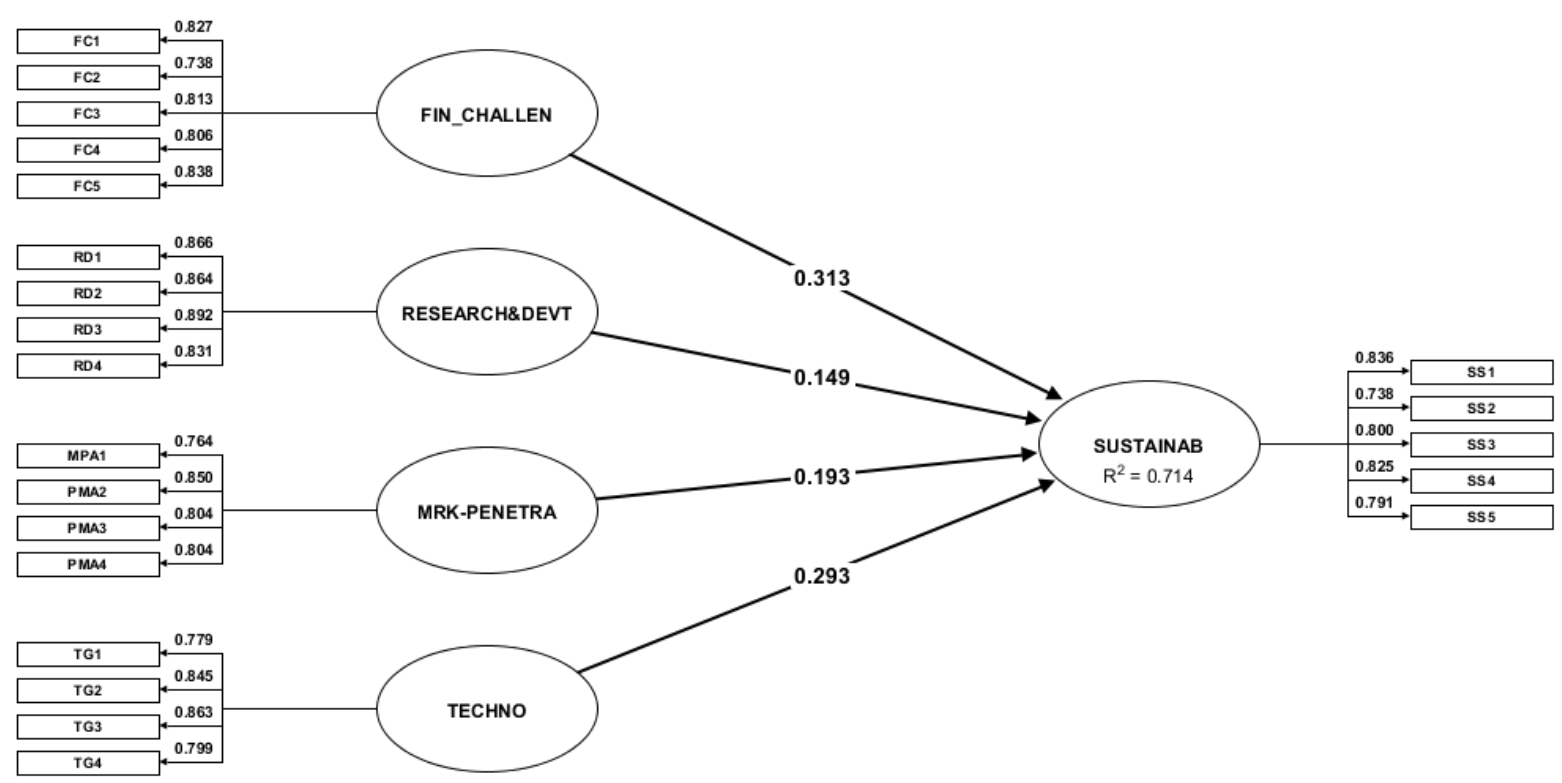

(Source: Authors' processing from ADANCO 2.2.1 Version)

\section{DISCUSSION}

This research aimed to investigate the mitigating factors warranting SMEs' sustainability in a developing country particularly Ghana. Our findings discovered that factors such as financial challenges, market penetration, and acceptability, technology, research, and development affect SMEs' sustainability in most developing nations with Ghana as a case study. The results of the findings clearly show that $\mathbf{H 1}$ : lack of financial assistance would significantly affect SME's sustainability. This suggests that financial challenge is one of the major factors warranting SMEs' sustainability in most developing countries. Such analogy is in agreement with the scholarly works of (Amoah \& Jibril, 2020; Kwaku Amoah, 2018; Pandya, 2012). In this regard, the researchers are of the view that financial challenges have contributed negatively to SMEs' 


\section{INTERNATIONAL JOURNAL OF ENTREPRENEURIAL KNOWLEDGE}

Issue 1, volume 9, ISSN 2336-2960 (Online)

www.ijek.org

sustainability. Additionally, provision and access to finance would cushion SMEs' performance which will land them in sustainability.

Also, from the PLS-SEM findings of the present study, H2: lack of research and development would negatively affect the Sustainability of SMEs is proven by the available results. The results above affirm our hypothesis. According to (Ensari \& Karabay 2014; Adom et al., 2014; Herath, H. A., \& Mahmood, 2013), research and development have immensely continued to affect SMEs' sustainability because most of these SMEs cannot conduct modern-day research which would contribute positively to their business activities. Thus, the opinion of the researchers is that since lack of research and development affects SMEs negatively, much attention should be given to it because new business ideas, product modification, and innovations among others would be revealed through this medium to meet customers' needs and demands.

Moreover, the valid responses received from the data collection process and analyzed through PLS-SEM revealed that SMEs' sustainability is hence affected by the failure of market penetration and product acceptability in both local and global markets (H3). Studies conducted by (White et al 2014; Haseeb et al., 2019) affirms that most products and services from developing countries suffer market penetration and acceptability. This has negatively limited their sustainability period in operations. The inability of SMEs to penetrate the market both locally and internationally has retarded their profitability and long-term viability. The researchers thus opined that entrepreneurs and business owners should regularly modify their products and services to meet the international and continental standards for them to enjoy the long-term benefits of sustainability.

Undoubtedly, H4: lack of modern-day technology by SMEs would negatively affect their sustainability is true from the available findings of the present study. According to (Qalati et al. 2021; Singh et al., 2019), the above hypothesis statement is a positive one. In their works, it was established that SMEs in most developing countries still manage their businesses with traditional approaches. These have resulted in low productivity, low quality of products and services to local and international markets. In response to this, the researchers wish to encourage entrepreneurs and business owners to apply modern-day technologies in their business dealings and transactions since the impact of technology nowadays cannot be underestimated due to the existence of ICT.

Finally, entrepreneurs and business owners in most developing countries are always concerned about however their businesses can be sustained in the long term. From the negative and empirically proven results on factors warranting SMEs and their sustainability under $\mathrm{H} 1, \mathrm{H} 2, \mathrm{H} 3$, and $\mathrm{H} 4$, the overall effect would be that factors like financial challenges, research, and development, market penetration and acceptability, technology would significantly affect SMEs sustainability is negatively established. That is to say, the combined effect of these factors would consequently hinder the survival of SMEs operation in the developing economies given the swift growth of innovation in the $21^{\text {st }}$ century business environment. Therefore, the findings agree with (Wang, 2016; Amoah \& Jibril, 2021) that such factors warrant SMEs' sustainability in the long run. Furthermore, since business dynamism has changed recently, SMEs are to embrace such changes to operate for a longer period and enjoy the benefits of business sustainability.

\section{CONCLUSION}

In this study, the researchers investigate the mitigating factors warranting SMEs Sustainability in a developing country setting, particularly, Ghana, a Sub-Sahara African region. Notably, conducting such research on SMEs in a developing nation like Ghana is very important since SMEs found in such countries contribute immensely to the development and growth of the nation. The results of our empirical analysis have shown that lack of financial assistance, lack of research and development, failure 


\section{INTERNATIONAL JOURNAL OF ENTREPRENEURIAL KNOWLEDGE}

Issue 1, volume 9, ISSN 2336-2960 (Online)

www.ijek.org

of market penetration and product acceptability, lack of modern-day technology affect SMEs' sustainability in Ghana. This supports H1. The study discovered that lack of financial assistance significantly affected SMEs' sustainability. It had a coefficient of $(\beta=0.3132)$. Again, $H 2$ is also supported. The study found out that lack of research and development negatively affected the sustainability of SMEs in the manufacturing sector in Ghana. It had a coefficient of $(\beta=0.1489)$.

The study also supported H3. The study discovered that the failure of SMEs to be able to penetrate the market and their product been accepted has been a major setback for SMEs sustainability within the manufacturing sector in Ghana. It had a coefficient of $(\beta=0.1930)$. The study also supported $H 4$. The research found out that the lack of modern-day technology undoubtedly affected SMEs' sustainability negatively. It had a coefficient of $(\beta=0.2928)$.

From the foregoing discussion, this study strongly believes that SMEs can be sustainable if they are provided with financial assistance, contribute to research and development when their product can penetrate the market and are accepted by customers. Lastly, SMEs should also adopt modern technology to compete and meet up both local and foreign standards.

Using a quantitative research approach, a structured questionnaire was used in collecting data from SMEs in the manufacturing sector of the economy from the central and western parts of the country through the online survey approach and self-administered approach. A simple random sampling technique was adopted in selecting the respondents for the answering of the questionnaire. Application of partial least square and structural equation modeling (PLS-SEM, ADANCO 2.0) results from 370 valid responses supported the hypotheses. However, the researchers used constructs like financial challenges, technology, market penetration and acceptability, research, and development to measure how it affects the sustainability of SMEs in this part of the world. Practically, entrepreneurs, business owners, and managers would take inspiration from the results/findings of the present study to formulate possible decisions that will help them to maintain in the business and develop strategies to eliminate or reduce the impact of such factors on their sustainability. Theoretically, the present study would also help other researchers and scholars to conduct further studies on the underlying constructs to test their validity and reliability in other developing countries. Since the study focused only on Ghana, the results or findings obtained cannot be generalized to other developing countries since the sample size is relatively small for such generalization.

\section{REFERENCES}

Abor, J., \& Quartey, P. (2010). Issues in SME development in Ghana and South Africa. International research journal of finance and economics, 39(6), 215-228.

Abou-Shouk, M. A., Lim, W. M., \& Megicks, P. (2016). Using competing models to evaluate the role of environmental pressures in ecommerce adoption by small and medium sized travel agents in a developing country. Tourism Management, 52, 327-339. https://doi.org/10.1016/j.tourman.2015.07.007

Adom, P. K., Amakye, K., Doh, E., \& Anku, R. (2014). SMEs record keeping in Ghana: Has VAT made it better?. International Journal of Economics and Financial Issues, 4(1), 152.

Ahmedova, S. (2015). Factors for increasing the competitiveness of small and medium-sized enterprises (SMEs) in Bulgaria. Procedia-Social and Behavioral Sciences, 195, 1104-1112. https://doi.org/10.1016/j.sbspro.2015.06.155

Amoah, J., \& Jibril, A. B. (2020). Inhibitors of social media as an innovative tool for advertising and MARKETING communication: Evidence from SMEs in a developing country. Innovative Marketing. https://doi.org/10.21511/im.16(4).2020.15

Amoah, J., \& Jibril, A. B. (2021). Social Media as a Promotional Tool Towards SME's Development: Evidence from the Financial Industry in a Developing Economy. Cogent Business of 


\section{INTERNATIONAL JOURNAL OF ENTREPRENEURIAL KNOWLEDGE}

Issue 1, volume 9, ISSN 2336-2960 (Online)

www.ijek.org

Management, 8(1), 1923357. https://doi.org/10.1080/23311975.2021.1923357

Amoah, J., Belás, J., Khan, K. A., \& Metzker, Z. (2021). Antecedents of Sustainable SMEs in the Social Media Space: A Partial Least Square-Structural Equation Modeling (PLS-SEM) Approach. Management \& Marketing, 16(1). https://doi.org/10.2478/mmcks-2021-0003

Amoah, S. K., \& Amoah, A. K. (2018). The role of small and medium enterprises (SMEs) to Employment in Ghana. International Journal of Business and Economics Research, 7(5), 151-157.

Ayyagari, M., Demirgüç-Kunt, A., \& Maksimovic, V. (2011). Small vs. young firms across the world: contribution to employment, job creation, and growth. World Bank Policy Research Working Paper, (5631). 10.11648/j.ijber.20180705.14

Belas, J., Amoah, J., Petráková, Z., Kljuchnikava, Y., \& Bilan, Y. (2020). Selected factors of SMEs management in the service sector. Journal of Tourism and Services. https://doi.org/10.29036/jots.v11i21.215

Bloom, N. et al. (2010) 'Why do firms in developing countries have low productivity?', American Economic Review, 100(2), pp. 619-623. DOI: 10.1257/aer.100.2.619.

Chatterjee, S., \& Kar, A. K. (2020). Why do small and medium enterprises use social media marketing and what is the impact: Empirical insights from India. International Journal of Information Management, 53, 102103. https://doi.org/10.1016/j.ijinfomgt.2020.102103

Denicolai, S., Zucchella, A., \& Magnani, G. (2021). Internationalization, digitalization, and sustainability: Are SMEs ready? A survey on synergies and substituting effects among growth paths. Technological Forecasting and Social Change, 166, 120650. https://doi.org/10.1016/j.techfore.2021.120650

Dijkstra, T. K., \& Henseler, J. (2015). Consistent and asymptotically normal PLS estimators for linear structural equations. Computational statistics \& data analysis, 81, 10-23. https://doi.org/10.1016/j.csda.2014.07.008

Eniola, A. A. (2014). The role of SME firm performance in Nigeria. Arabian Journal of Business and Management Review (OMAN Chapter), 3(12), 33.

Ensari, M. Ş., \& Karabay, M. E. (2014). What helps to make SMEs successful in global markets?. ProcediaSocial and Behavioral Sciences, 150, 192-201. https://doi.org/10.1016/j.sbspro.2014.09.030

Hair, J. F., Risher, J. J., Sarstedt, M., \& Ringle, C. M. (2019). When to use and how to report the results of PLS-SEM. European business review. https://doi.org/10.1108/EBR-11-2018-0203

Hair, J., Hollingsworth, C. L., Randolph, A. B., \& Chong, A. Y. L. (2017). An updated and expanded assessment of PLS-SEM in information systems research. Industrial Management \& Data Systems. https://doi.org/10.1108/IMDS-04-2016-0130

Haseeb, M., Hussain, H. I., Kot, S., Androniceanu, A., \& Jermsittiparsert, K. (2019). Role of social and technological challenges in achieving a sustainable competitive advantage and sustainable business performance. Sustainability, 11(14), 3811. https://doi.org/10.3390/su11143811

Herath, H. A., \& Mahmood, R. (2013). Strategic orientation-based research model of SME performance for developing countries. Review of Integrative Business and Economics Research,2(1), 430.http://dx.doi.org/10.4172/2169-026X.1000119

Ji, H. (2011). The reasons and solutions for Chinese SMEs' financing dilemma. Journal of special zone economy in China, 2, 219-221.

Jibril, A. B., Kwarteng, M. A., \& Chovancova, M. (2019, May). A Demographic Analysis of Consumers' Preference for Green Products. In International Scientific Conference CONTEMPORARY ISSUES IN BUSINESS, MANAGEMENT AND ECONOMICS ENGINEERING (pp. 9-10). https://doi.org/10.3846/cibmee.2019.044

Jibril, A. B., Kwarteng, M. A., Chovancová, M., \& Denanyoh, R. (2019). The influence of selected factors on the use of herbal products. Journal of Competitiveness. https://doi.org/10.7441/joc.2019.04.04

Kachembere, J. (2011). Zimbabwe: SMEs Hold Key to Economic Growth. Online Business Studies.

Klapper, L. F., \& Love, I. (2010). The impact of business environment reforms on new firm registration. World Bank policy research working paper, (5493). https://ssrn.com/abstract=1721331

Kwaku Amoah, S. (2018). The Role of Small and Medium Enterprises (SMEs) to Employment in Ghana. International Journal of Business and Economics Research, 7(5), 151. 
INTERNATIONAL JOURNAL OF ENTREPRENEURIAL KNOWLEDGE

Issue 1, volume 9, ISSN 2336-2960 (Online)

www.ijek.org

https://doi.org/10.11648/j.ijber.20180705.14

Kwarteng, M. A., Jibril, A. B., Nwaiwu, F., Pilik, M., \& Ali, M. (2019, June). Internet-Based Channel Orientation for Domesticated Services Firm: Some Drivers and Consequences. In International Working Conference on Transfer and Diffusion of IT(pp. 90-103). Springer, Cham. https://doi.org/10.1007/978-3-030-20671-0 7

Lazányi, K., \& Amoah, J. (2020). Focus on internal stakeholders in Hungarian SMEs. In MEB-18th International Conference on Management, Enterprise, Benchmarking. Proceedings (MEB 2020).

Maduku, D. K., Mpinganjira, M. and Duh, H. (2016) 'Understanding mobile marketing adoption intention by South African SMEs: A multi-perspective framework', International Journal of Information Management. Elsevier Ltd, 36(5), pp. 711-723. DOI: 10.1016/j.ijinfomgt.2016.04.018.

Nnadi, C. (2014). Entrepreneurship development and its impact on small scale business enterprises in developing countries: A Nigerian experience. Journal of Entrepreneurship \& Organization Management, 3(2), 7. DOI: 10.4172/2169-026X.1000119

Pandya, V. M. (2012, September). Comparative analysis of the development of SMEs in developed and developing countries. In The 2012 International Conference on Business and Management (pp. 6-7).

Pournasir, S. (2013). Key success factors of strategic management implementation in SMEs in Iran. Journal of International Studies, 6(2), 65-78. DOI: 10.14254/2071-8330.2013/6-2/6

Qalati, S. A., Yuan, L. W., Khan, M. A. S. and Anwar, F. (2021). A mediated model on the adoption of social media and SMEs' performance in developing countries. Technology in Society 64 (2021) 101513. https://doi.org/10.1016/j.techsoc.2020.101513

Sanjo, O. M., \& Ibrahim, M. O. (2017). The effect of international business on SMEs Growth in Nigeria. Journal of Competitiveness, 9(3), 67-80. DOI: 10.7441/joc.2017.03.05

Singh, R. K., Luthra, S., Mangla, S. K., \& Uniyal, S. (2019). Applications of information and communication technology for sustainable growth of SMEs in India food industry. Resources, Conservation and Recycling, 147, 10-18.

Virglerova, Z., Conte, F., Amoah, J., \& Massaro, M. R. (2020). The Perception Of Legal Risk And Its Impact On The Business Of Smes. International Journal of Entrepreneurial Knowledge, 8(2), 1-13. doi: 10.37335/ijek.v8i2.115

Wang, Y. (2016). What are the biggest obstacles to growth of SMEs in developing countries? -An empirical evidence from an enterprise survey. Borsa Istanbul Review, 16(3), 167-176. https://doi.org/10.1016/j.bir.2016.06.001

White, G. R., Afolayan, A., \& Plant, E. (2014). Challenges to the adoption of e-commerce technology for supply chain management in a developing economy: a focus on Nigerian SMEs. In E-commerce Platform Acceptance (pp. 23-39). Springer, Cham. https://doi.org/10.1007/978-3-319-06121-4_2

Ye, J., \& Kulathunga, K. M. M. C. B. (2019). How does financial literacy promote sustainability in SMEs? A developing country perspective. Sustainability, 11(10), 2990. https://doi.org/10.3390/su11102990

Yin, Q. (2012). A study on the dilemma of China's small business finance (Doctoral dissertation, Doctoral Dissertation. Southwestern University of Finance and Economics).

\section{BRIEF DESCRIPTION OF AUTHORS:}

\section{John Amoah}

ORCID: 0000-0002-3558-2077

PhD Candidate, Faculty of Management and Economics, Tomas Bata University in Zlín, Mostní 5139, Zlin 760 01, Czech Republic

Email: jamoah@,utb.cz

Area of interest: Social Media Analysis, Consumer Behaviour, Entrepreneurship/SMEs Development 
INTERNATIONAL JOURNAL OF ENTREPRENEURIAL KNOWLEDGE

Issue 1, volume 9, ISSN 2336-2960 (Online)

www.ijek.org

\author{
Abdul Bashiru Jibril \\ ORCID: 0000-0003-4554-0150 \\ PhD Candidate \\ Faculty of Management and Economics, Tomas Bata University in Zlín, Mostní 5139, Zlin 760 01, \\ Czech Republic \\ E-mail: jibril@utb.cz \\ Area of interest: Internet Marketing Applications, Social Media Analysis, Brand Management
}

\title{
Bayuasi Nammei Luki
}

ORCID: 0000-0002-2575-0516

PhD Candidate

Faculty of Information Technology Business, Ghana Communication Technology University

Email: blukki@gctu.edu.gh

Area of interest: Natural resource management, HRM practices, entrepreneurship/SMEs

\section{Michael Amponsah Odei}

ORCID: 0000-0001-9449-5750

PhD Candidate

Tomas Bata University in Zlín, Faculty of Management and Economics, Mostní 5139, 76001, Zlín, Czech Republic

Email: Odei@,utb.cz

Area of interest: Innovation, Technology Transfer and Patents

\section{Charles Yawson}

ORCID: 0000-0002-5290-2239

PhD Candidate

Faculty of Information Technology Business, Ghana Communication Technology University

Email: yawson@gctu.edu.gh

Area of interest: Consumer behaviour, Digital Marketing, Sustainability 